to definition and morphogenesis. Am J Cardiol 1977;40: 569-78.

9. Di Donato RM, Fyfe DA, Puga FJ, et al. Fifteen-year experience with surgical repair of truncus arteriosus. J Thorac Cardiovasc SURG 1985;89:414-22.

10. Lacour-Gayet F, Bruniaux J, Serraf A, Sousa-Uva M, Roux D, Planché C. Influence of pulmonary valve competence on truncus arteriosus repair. Cardiol Young 1993; 3(Suppl): 13 .

\section{Use of topical sodium nitroprusside to relieve perioperative spasm of the internal mammary artery: $A$ word of caution}

\section{To the Editor:}

After reading with interest the article by Cooper, Wilkinson, and Angelinil concerning perioperative spasm of the internal mammary artery (IMA), we used sodium nitroprusside topically in two consecutive patients undergoing coronary artery bypass operation to relieve the spasm of the left IMA before closure of the sternotomy. The concentration of sodium nitroprusside used was that proposed by these authors, $2 \mathrm{mg}$ in $4 \mathrm{ml}$ of $5 \%$ dextrose in water. We report here the cases of these two consecutive patients, in whom significant drops in the arterial blood pressure occurred immediately after the sodium nitroprusside was sprayed on the IMA pedicle.

CASE 1. A 61-year-old man underwent a coronary artery bypass operation with a left IMA graft to the left anterior descending artery and supplemental sequential saphenous vein grafts to the first and second marginal branches of the circumflex artery. The left IMA was dissected on a pedicle with the aid of electrocautery and titanium hemoclips. Papaverine at $6 \mathrm{mg}$ in $0.9 \%$ normal saline solution was sprayed on the pedicle after dissection. After completion of proximal anastomoses, the patient was weaned from bypass with satisfactory hemodynamics and was decannulated. The left IMA was noticed to be spastic before closure of the sternotomy, and $2 \mathrm{mg}$ sodium nitroprusside in $4 \mathrm{ml} \mathrm{5 \%}$ dextrose in water was sprayed on the IMA pedicle. Systolic arterial blood pressure fell to $30 \mathrm{~mm} \mathrm{Hg}$ within seconds after the vasodilator was sprayed on. This low blood pressure was not responsive to the infusion of fluids and necessitated the use of vasoactive agents. An intravenous injection of $500 \mu \mathrm{g}$ metaraminol was given. Despite volume infusion and metaraminol treatment, peripheral vascular collapse persisted and epinephrine was infused at a rate of $4 \mu \mathrm{g} / \mathrm{min}$. The patient's state of peripheral vascular collapse gradually resolved during the next 15 minutes, and the patient was transferred to the intensive care unit with stable hemodynamics.

CASE 2. A 57-year-old woman underwent coronary artery bypass operation with a left IMA graft to the left anterior descending artery and a supplemental saphenous vein graft to the first diagonal artery. The left IMA was prepared as described in case 1. The IMA was noted to be spastic after decannulation, and $2 \mathrm{mg}$ sodium nitroprusside in $4 \mathrm{ml} \mathrm{5 \%}$ dextrose in water was therefore sprayed on the IMA pedicle. Arterial blood pressure fell immediately after the vasodilator was sprayed on. Rapid fluid infusion and $500 \mu \mathrm{g}$ metaraminol by intravenous injection were enough to reverse peripheral vascular collapse. The patient was transferred to the intensive care unit in stable condition.

Early postoperative spasm of the IMA is a serious condition that can result in significant morbidity and mortality. ${ }^{2,3} \mathrm{CoO}-$ per, Wilkinson, and Angelini ${ }^{1}$ recommended the topical use of sodium nitroprusside for immediate relief of IMA spasm. Although they stated that they used the maximum concentration that did not produce any undesirable drop in systemic arterial blood pressure, the same concentration caused a significant drop in blood pressure in our two patients.

We believe that a significant drop in blood pressure as a result of absorption of drug from the soft tissues is always a possibility with the use of sodium nitroprusside. Concentration of drug should be tailored to each patient.

Harun Tatar, $M D$

Sertaç Ciçek, $M D$

Hikmet Süer, $M D$

Ahmet T. Yilmaz, MD

Ömer $Y$. Öztürk, $M D$

R. Dündar Narbay, $M D$

Department of Cardiovascular Surgery GATA, Gülhane School of Medicine Etlik, 06018, Ankara, Turkey

\section{REFERENCES}

1. Cooper GJ, Wilkinson GAL, Angelini GD. Overcoming perioperative spasm of the internal mammary artery: which is the best vasodilator? J THORAC CARDIOVASC SURG 1992; 104:465-8.

2. Sarabu MR, McClung JA, Fass A, Reed GE. Early postoperative spasm in the left internal mammary artery bypass grafts. Ann Thorac Surg 1987;44:195-200.

3. Jones EL, Lattaf OM, Weinstaub WS. Catastrophic consequences of internal mammary artery hypoperfusion. $\mathbf{J}$ Thorac Cardiovasc Surg 1989;98:902-7.

\section{Case report of isolated and abnormal drainage of right superior vena cava into left atrium}

\section{To the Editor:}

This case report describes the diagnosis and successful surgical treatment of abnormal venous drainage of the head and neck into the left atrium of a 9-year-old girl. After extensive review of the literature, ${ }^{1-3}$ we believe this is the sixth case of this rare congenital anomaly and the first case described as pure drainage of a right superior vena cava into the left atrium. Table I shows results of oximetry. Figs. 1 and 2 show the results of injection of contrast material into the heart. The radiopaque material ended up in the aorta.

A 9-year-old white girl was referred to this center because of cyanosis and underwent an extensive workup. Her operation was performed through a standard median sternotomy incision, without cardiopulmonary bypass. A direct anastomosis of the superior vena cava into the right atrium was accomplished with

Table I. Cardiac catheterization data

\begin{tabular}{lccccc}
\hline & $R A$ & $R V$ & $P A$ & Aorta & $L V$ \\
\hline $\begin{array}{c}\text { Oxygen } \\
\text { saturation } \\
(\%)\end{array}$ & 68 & 68 & 68 & 82 & 84 \\
$\begin{array}{c}\text { Pressure } \\
(\mathrm{mm} \mathrm{Hg})\end{array}$ & $\overline{7}$ & $40 / 0-7$ & $40 / 10, \overline{19}$ & $130 / 65, \overline{80}$ & $110 / 2$ \\
\hline
\end{tabular}

